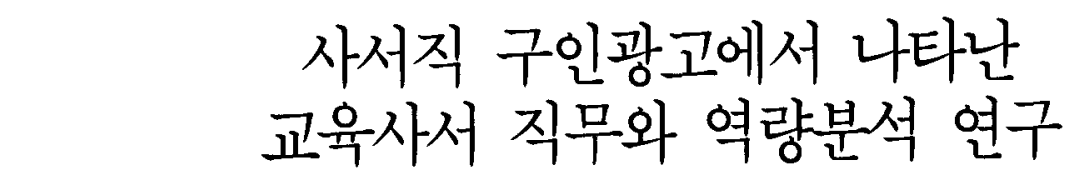

\title{
An Analysis on the Roles, Responsibilities, and Job Qualifications of Instruction Librarians in Librarian Job Ads
}

최 상 희(Sang-Hee Choi)*

\begin{tabular}{|l|l|}
\hline 1. 서 론 & 차 \\
2. 도서관의 교육적 역할과 사서직의 변화 & 4.1 교육사서 직명에서 나타나는 관련 \\
3. 연구개요 & 4.2 겁무육사서의 주요 직무 \\
3.1 연구 방법 및 과정 & 4.3 교육사서의 주요 자격요건 \\
3.2 사서직 구인광고 유형별 분포 & 5. 결 론 \\
4. 교육관련 사서의 직무 및 자격요건 &
\end{tabular}

\section{초 록}

도서관에서 교육 분야가 주요 영역으로 인식되어 가면서 수행되고 있는 교육활동도 점차 다양한 분야로 확장되어 가고 있다. 이러한 변화에 따라 교육을 담당하는 사서 역할의 중요성도 강조되고 있다. 이 연구에서는 구인광고에 나타난 도서관의 교육 사서 모집현황을 통하여 교육사서의 역할과 자격요건을 분석하여 도서관의 교육활동 분야의 특성을 분석하고자 하였다. 분석 결과 교육사서의 업무 중 참고봉사와 장서개발 업무에 대한 역할과 자격요건이 교육관련 업무와 유사하게 중요한 것으로 나타났고 웹과 교육관련 어플리케이션 등 정보기술에 대한 중요성도 강조되고 있는 것으로 밝혀졌다.

\section{ABSTRACT}

Instruction is an emerging critical factor of library services and the practice of instructional activities has expanded to related various areas. This study analyses librarian job advertisements to identify roles, responsibilities, and job qualifications of instruction librarian. Findings include reference services and collection development are important parts for instruction librarians work as well as instructional activities. Knowledge on web and instructional applications are also emphasized in the job description of instruction librarians.

키워드: 도서관, 교육 사서, 사서직, 직무, 역량, 구인광고

Instruction Librarian, Job Description, Job Responsibilities, Job Qualification. Skills, Job Advertisements

\footnotetext{
* 한국학술진흥재단 전문위원(shchoi01@krf.or.kr)

논문접수일자 2007 년 9 월 5 일

게재확정일자 2007 년 9 월 27 일
} 


\section{1. 서 론}

도서관은 이용자에게 정보를 제공하고 이용 을 지원하는 기관으로 역할을 규정하고 있지만. 참고봉사 서비스와 대출 서비스를 제외하고는 사서직의 인력이 이용자와 대면하는 서비스에 적극적으로 참여하지 못하고 있는 것이 현실이 다. 따라서 이용자 중심의 서비스를 목표로 하 면서도 사서들이 정작 이용자에게 직접적인 접 근 통해 서비스를 제공하는 업무는 비중이 크 지 못하다. 이와 같은 도서관 사서업무의 이용 자에 대한 소극적인 서비스에 변화가 나타나고 있는데 그 중 한 영역이 교육분야이다. 교육분 야는 적극적으로 이용자와 대면하는 형태의 서 비스이며 서비스 방법과 유형, 내용이 매우 다 양하게 구성될 수 있기 때문에 도서관에서 발 전방향을 모색할 때 고려되는 주요 분야이다. 도서관의 정보자원과 서비스를 바탕으로 하는 교육활동에서부터 특정 분야의 전문적인 내용 을 다루는 전문성이 있는 교육활동, 일반인을 대상으로 하는 정보활용능력 교육 등 교육과 관련된 프로그램이 점차 다양화되고 있다.

이와 같은 변화에 영향을 받아 도서관에서 교육을 전담하는 전문직, 즉 교육 사서에 대한 필요성도 점차 구체적으로 나타나고 있다. 그 러나 실제 어떤 분야의 사서가 어떤 명칭으로 어떤 내용의 직무를 하는지에 대한 구체적인 분석은 미흡한 편이다. 특히 국내에서는 주제 전문사서도 활성화되고 있지 못한 시점에서 상 대적으로 새로운 사서직인 교육사서에 대한 수 용 가능성에 대하여 세부적인 연구가 필요하다. 이 연구에서는 미국에서 나타나고 있는 교육사 서에 대한 구인광고를 분석하여 교육사서의 실
제적인 직무내용과 자격요건을 파악한 후 도서 관에서 일어나고 있는 교육분야의 변화를 파악 하고자 하였다. 이러한 변화는 도서관에서 새 로 수급하고자 하는 인력에 대한 요구사항과 기대하는 수행업무에 직 - 간접적으로 표현되 어 있을 수 있으며, 이를 분석한다면 실제 도서 관 현장에서 일어나고 있는 사서직의 업무 변 화에 관한 현상을 파악할 수 있기 때문이다. 이 연구의 결과는 국내 도서관에서도 사서의 업무 가 향후 다양한 영역으로 개척해나가기 위한 기초자료로서 활용될 수 있을 것이다.

\section{2. 도서관의 교육적 역할과 사서직의 변화}

도서관에서 교육분야가 중요한 업무의 하나 로 부각되면서 도서관에서 수행하고 있는 각종 교육 관련 업무들을 표현하는 용어들도 다양하게 등장하기 시작했다. 도서관 투어(library tour), 도서관 오리엔테이션(library orientation), 서 지교육(bibliographic instruction), 도서관 교육 (library instruction), 도서관 연구 코스(Library research courses), 이용자 훈련(user training), 이용자 교육(user education), 도서관 이용기술 교육(library skills instruction), 도서관 고객 교육(library customer education), 정보활용 기술 교육(information skills instruction), 연 구 교육(research instruction) 등이 도서관에 서 수행하고 있는 교육 관련 용어들이다. 도서 관 서비스 영역의 연구자들은 이러한 용어가 혼 재되어 사용하는 것을 문제로 제기하고 있다. 그러나 Clyde(2005)는 도서관에서 교육에 관 
련된 용어들을 반드시 통일시킬 필요는 없으며, 오히려 도서관의 환경과 목적에 따라 다양하게 나타나는 것이 바람직하다고 언급하였다. 그는 이러한 용어의 다양성은 사서의 교육 관련 역할 에 대한 폭넓은 기대치를 표현하는 것이라고 기 술하였다. 클라이드는 정보활용의 중요성이 점 점 강조되면서 정보활용에 기여하는 사서의 역 할에 대하여 논의가 활발하게 이루어지고 있고. 이러한 현상이 사서의 전문성 개발에 어떤 영향 을 미치는가를 조사하는 것이 중요하다고 강조 하였다. 그의 연구에서 현 도서관의 정보활용 교육과 트레이닝을 위해 필요로 하는 지식과 기 술에 대한 요구사항을 분석하기 위하여 2001년 12 월부터 2002년 2월까지 3개월간 'LIBJOBS listserve'에 올라온 구인광고를 분석하였다.

3 개월간 구인 광고 중 “library orientation', 'use education', 'information literacy instruction', 'information skills development', 'library skills instruction', 'bibliographic instruction', 'training' 등의 개념을 포함한 구인광고 150 건을 분석하 였다. 이 중 교육과 관련한 사항이 포함된 광고 를 모두 분석한 결과, 이 기간 동안 게재된 광고 291건 중 150건이 교육과 관련된 것으로 나타났 다. 즉, 3 개월 동안 나타난 구인광고 중 $51.5 \%$ 에 해당하는 광고에서 교육과 관련된 직무를 언급한 것이다. 세부적으로 살펴보면 포지션 자체가 교육전담인 경우는 $8.7 \%$ 로서 높은 비 율을 차지하는 것은 아니지만 교육이 주요직무 로서 나타난 경우는 $54.7 \%$ 로 나타났고, 부분 직무인 경우는 $36.7 \%$ 에 해당하는 것을 알 수 있었다. $54.7 \%$ 에 해당하는 구인광고의 직종명 (job title) 을 분석한 결과, 직종명에서는 교육과 관련된 사항이 나타나지 않았고 주로 담당하게
될 직무(job description)에서 도서관 교육 프로 그램 개발 또는 교육참여 등의 내용이 언급되어 있었다. 이 연구에서는 구인광고 중 교육과 관 련하여 게재된 광고의 분포 비율만을 분석하였 기 때문에 교육을 전담하는 직종명을 분석하저 나 필요 자격요건, 주요 책임 직무 등과 같이 도 서관 사서 직종에 나타나고 있는 교육 담당 직 종에 대한 현상을 세부적으로는 설명하는데 한 계가 있었다. 그러나 이 분석 결과는 사서 직무 중에서 교육관련 부분이 일반화되고 있다는 동 향은 뚜렷하게 보여주고 있다.

교육업무와 관련된 사서의 역할에 대한 기대 수준의 변화는 여러 연구에서도 분석될 수 있 다. Fourie(2004)의 연구에서는 문헌연구를 통 해 사서의 역할 변화를 분석하였는데 사서의 역할이 새롭게 변화하고 확장되어야 할 영역으 로서 사서의 문화적 역할, 강의역할, 정보접근 제공 역할, 공간설비에 대한 역할에 대해 강조 하였다. 그 중 교육과 관련된 사서의 역할은 다 음과 같다.

첫째, 강의의 역할이다. 정보활용교육, 미디 어 교육, 서지교육, 도서관 오리엔테이션, 정보 연구능력 교육 등 도서관에서 정보검색 및 활 용에 있어 협력적인 역할을 강조하는 환경으로 변화하고 있는데, 저자는 사서가 이용자의 정 보이용 역량을 향상시킬 수 있는 준비가 되어 있는가에 문제를 제기하였다. 둘째, 정보접근 제공 역할이다. 전자적 정보원이 늘어나면서 정보에 대한 접근을 제공하는 서비스가 강조됨 에 따라 이용자들이 접근을 효율적으로 할 수 있도록 교육적 지원을 제공하고 원격교육의 범위까지 사서의 역할 범위를 확대할 필요가 있다. 셋째, 출판의 역할이다. 이것은 사서가 웹 
트레이닝 자료, 도움말 자료, 트레이닝 매뉴얼, 각종 교육 자료 등을 출판하는 경우에 대해 언 급하고 있다. 넷째, 컨설팅 역할이다. 일반적으 로 컨설팅 역할은 저작권이나. 지적 재산권에 대해 다루고 있으나. 여기에서는 그 의미를 확 대하여 연구에 대한 컨설팅 업무도 도서관에서 수행되고 있는 업무 중 하나이며 교육적 역할 이 강조되는 영역으로 보고 있다.

국내 사서직의 업무변화를 통시적으로 분석 한 연구로 1970년부터 1980년대까지의 업무와 2000 년대의 업무를 비교한 사례가 있다. 이 연 구에서는 도서관법과 기준, 담당부서 및 정책, 직문분석을 통해 사서업무의 환경변화와 직무 변화를 파악하고자 하였다. 분석의 결과, 1980 년대에는 약 $70 \%$ 에 해당하는 사서의 업무가 관리업무에 초점이 맞추어져 있었다면, 2000년 대에는 사서의 업무가 이용자에 대한 서비스와 디지털 정보환경을 중심으로 하는 업무로 다양 화되고 있는 것으로 나타났는데 그 중 한 영역 이 교육, 정보서비스의 업무이다(안인자 2005).

사서의 교육적 역할이 확대되는 현상을 분석 한 연구 중 구체적으로 사서업무를 세분화하여 교육전담 사서의 역할을 분석한 사례로는 Shank (2004)의 연구가 있다. 이 연구에서는 1999년 부터 2004년간 "College \& Research Libraries News', 'Library Journal', 'The Chronicle of Higher Education', '인터넷 구인 토론리스트 (libjobs)', 'Educause'에 올라온 구인광고 중 "instructional designer"와 "librarian"이라는 용어 가 포함되어 있는 광고를 대상으로 "instructional design librarian"의 역할과 자격조건에 대하여 분석하였다. 이 연구에서 분석된 "instructional design librarian"의 주요 자격요건을 살펴보면
웹과 멀티미디어 어플리케이션 이용 능력, 커뮤 니케이션과 대인상대 능력(interpersonal skills), 조직적 능력(organizational skills), 교육 공학 기술(instructional technologies skills) 과 경험 (experiences) 순으로 중요도가 나타났다. 주 요 책임업무로는 온라인과 웹 정보원, 각종 툴 (tools) 을 생산하는 업무가 가장 많은 것으로 나타 났고 두 번째로는 교육 공학 기술(instructional technologies skills)이 차지했고, 다음으로 도. 서관 교육 프로그램 업무가 언급되었다. 그 다 음 순으로 평가, 참고봉사, 교원과 직원 훈련 프 로그램, 정보활용, 연구 등의 순으로 나타났다. 멀티미디어 전자 정보원의 출현과 전자적인 형태의 새로운 서비스가 활성화되면서 참고봉 사 업무는 교육과 관련되어 급변하고 있는 사서 직무 중 하나가 되었다. 도서관에서 담당하는 교육의 범위가 넓어지면서 직간접적으로 참고 사서의 직무도 변화하고 있다. Auster와 Chan (2004)의 참고사서의 역할 변화를 분석한 연구에 따르면 기본적인 참고사서의 역할 외에도 기술적 능력(technological skills), 운영능력(management skills), 교육능력(instructional skills) 등이 중 요한 요소로 떠오르고 있다고 하였다. 특히 교 육부문에서 살펴보면 과거에는 서지교육이 참 고사서의 한 업무로 인식되어 왔으나, 현재 도 서관에서 수행되고 있는 교육은 다양한 주제분 야에 대해 여러 가지 형태로 확장되어 나타나 고 있다는 분석결과를 제시하였다. 또한 이들 은 도서관에서도 교육의 형식이 강의 수준의 형태로 발전되어야 할 것을 제언하였다.

도서관 사서가 실시하는 강의에 대한 요구로 서 정보활용, 정보연구능력(information research skills), 미디어 활용능력과 같은 분야에서 교육 
관련 강의에 대한 요구가 지속해서 증가하고 있다(Kibridge and DePalo 2001). 특히 디지 털도서관이 발달하면서 원격 이용자와 원격교 육 학생들의 요구수준은 높아지고 있는 상황이 다. 따라서 이들의 요구에 부응하기 위해 도서 관 사서들도 원격교육의 원칙에 대해 교육받아 야 하고 원격교육 수강생의 요구사항에 대하여 깊이 있게 인지할 필요가 있다(Hoerman and Furniss 2001).

도서관과 교육에 대하여 나타나고 있는 현상 들을 정보활용에 초점을 맞추어 분석한 Marcum (2002)의 연구에서는 사서들이 지난 10 년동안 정보활용(information literacy)이라는 요소를 중요하게 인식하고 추구하기 시작했음을 보여준 다. 이러한 변화는 특히 대학도서관(academic libraries)에서 현저하게 나타나기 시작했다. 대 학도서관에서 교육에 대한 요구가 증가되고 있 다고 보여주는 현상 중 하나는 최근 10 년간 대 학도서관의 교육관련 기준과 지침이 지속적으 로 만들어지기 시작했다는 점에서 찾아볼 수 있 다. 영국의 경우는 1999년 "Information Skills in Higher Education from the Standing Conference of National and University Librarians", 마국의 경우에서도 미국 대학도서관 협회 의 "Information Literacy Competency Standards for Higher Education(2000)", "The Objectives for Information Literacy Instruction: A Model Statement for Academic Librarians(2001)", "Assessing Student Learning Outcomes in Information Literacy Programs (2002)." 등을 발표함으로써 대학도서관의 교 육에 대한 방향성을 제시하였다. 한편 도서관 2.0에 초점을 맞추어 본 대학도서관 사서역할
의 변화에 관한 국내의 연구에서는 대출사서의 교육적 역할을 제시한 경우(이현실 2007) 가 있 어 참고사서의 교육적 역할을 강조한 해외 연 구와는 다른 접근을 보여주었다.

공공도서관에서는 이와는 다르게 대학도서 관처럼 활발하게 정보활용을 포함한 교육에 대 한 요구가 강하게 인식하고 있지는 않다는 조 사결과가 발표되었다. 온타리오 공공도서관 참 고사서를 대상으로 한 조사에서 사서들이 전문 성 강화를 위해 투자해야할 분야로서 가장 많 이 응답을 한 항목으로서 "인터넷 어플리케이 션”과 “전자정보원에 대한 전문성 확보”로 나 타나 각각 $83.7 \%$ 와 $83.0 \%$ 를 차지하였다. 반면 에 "교육적 기술(instructional techniques)" 이라고 응답한 경우는 $38.0 \%$ 로 상대적으로 낮 은 수치를 보였다(Auster and Chan 2004). 이 러한 결과는 연구의 저자인 Auster가 문헌연구 를 통해 교육적 역할의 중요성이 증가하고 있 을 것이라고 예측한 것과는 달리 공공도서관에 서는 교육 보다 정보기술적인 요소에 대하여 사서가 전문성을 확보해야 한다는 인식이 중요 하게 생각되고 있음을 알 수 있다.

\section{3. 연구개요}

\section{1 연구 방법 및 과정}

도서관에서는 일반적으로 새롭게 발전하는 분야에 대한 인력을 새로운 인력으로 수급하는 경향이 있고 이러한 새 인력에 대한 요구사항은 구인광고에서 반영되게 된다. 따라서 구인광고 내용에 표현되어 있는 교육분야에서의 인적자 
원의 역량에 대해 내용분석을 실시한다면, 실제 도서관에서 추구하고자 하는 교육 활동에 대한 현황을 도출할 수 있다. 구인광고는 일반적으로 구인을 하는 기관 소개와 해당 직종에 대한 정 보 직무, 자격요건 등으로 구성되어 있다.

구인광고를 분석하여 도서관의 업무 변화 및 사서직 변화를 살펴보고자 한 연구로서는 린치 (Lynch and Smith 2001)의 연구가 있는데, 이 연구는 구인광고에서 나타나는 사서직의 변 화을 분석하여 대학도서관의 변화를 파악하고 자 한 시도였다. 이 연구에서는 시대의 흐름에 따라 나타나는 사서직의 변화를 인지하기 위한 목적으로 1973년과 1998년 사이에 5년 간격으 로 1973년, 1983년, 1988년, 1993년, 1998년에 나타난 220 개의 구직광고를 내용 분석하였다. Lynch의 내용분석에서 사용한 사서직 유형은 1999년 미국도서관 도서관대회에서 사용했던 사서직 카테고리로서 그 내용은 다음 〈표 1〉과 같다.

구인광고를 내용분석한 또 다른 사례로서 정 리서비스 구인 광고를 분석한 경우가 있다. 이
연구는 1995년 Penny M. Belle과 Megan M. Adams가 광고를 분석하여 정리서비스 사서 현황을 분석한 연구방법을 적용하여 2001년 'Americal Libraries', 'AutoCat', 'The Chronocle of Higher Education', 'College and Research Libraries'에 게재된 광고를 분석한 후, 2001년 분석 연구 결과와 1995 년 연구의 결과를 비교 분석한 사례이다. 이 연구도 서로 다른 두 시대 의 구인광고를 비교분석함으로써 시간의 변화 에 따른 도서관과 사서직의 변화를 살펴보고자 한 시도이다.

본 연구에서도 교육과 관련하여 도서관의 역 할 변화와 사서직의 변화를 살펴보기 위하여 구 인광고에 대한 내용분석 방법을 적용하였다. 도 서관에서의 교육에 관련된 선진국 도서관의 현 황 분석과 발전 방향성을 파악하기 위해서 이 연구에서는 분석대상을 도서관의 교육적 역할 에 대하여 활발하게 논의가 일어나고 있는 미국 도서관의 구인광고 중 "American Libraries" 에 2004년부터 2006년간 게재된 구인광고를 대 상으로 하였다.

〈표 1〉1999년 미국도서관 도서관대회의 사서직 카테고리
A. Administration(deans, directors, etc)
A1. Other administrative positions(personnel officer, etc)
A2. Head of subject library
A3. Head of a library dept
D. General and subject reference
E1. Instruction librarian(coordinator of instruction)
E2. Extension/distance learning librarian
F. Technical services(acquisition, Cataloger, Serials)
H. Collection development
I. Special materials (government document, maps, rare books, archives, audiovisual etc)
J. Information systems(automation, bibliographic utilities, networks, systems, etc) 
수집된 광고는 광고를 게재한 주체별로 유형 을 분류하였고 각 연도별로 게재된 광고 중 교 육관련 사서직을 추출하기 위하여 린치(2001) 의 연구에서 사용된 1999년 사서직 카테고리를 기반으로 하여 〈표 2〉와 같은 사서직 유형 분류 표를 작성하였다. 린치의 사서직 카테고리에서 는 대출과 기록관리에 대한 유형이 없었으나 실제 구인광고에서는 대출과 기록관리 담당 사 서에 대한 수요가 있었고 장서개발은 수서와 연결되어 나타나고 있어 이러한 현황을 감안하 여 사서직 유형 분류표를 수정 보완하였다. 또 한 특정 업무가 지정되지 않고 도서관의 모든 업무에 참여하는 사서를 구인하는 경우도 상당 수 되어 이 경우를 '일반'으로 분류할 수 있도록 분류표에 추가하였다. 사서직 유형을 보다 세 부적으로 분류한 수정된 분류표를 통해 구인광 고 내의 사서직 유형 분포와 같은 일반적 현황 을 파악할 수 있었고, 교육관련 사서가 차지하
는 비율을 조사할 수 있었다. 또한 수정된 분류 표를 이용하여 세부 직무 및 자격요건을 분석 하기 위한 교육관련 사서 구인광고를 추출할 수 있었다. 분류과정에서 한 직종이 두 직무를 수행하는 경우에는 중복분류를 하였다.

각 유형별로 분류된 유형 중 교육 관련으로 분류된 구인광고에 대해서는 광고에 기술된 직 무와 자격요건을 세부적으로 분석하였고, 도서 관에서 요구하고 있는 교육 관련 업무 현황과 그에 적합한 인적자원에 대한 자격요건을 도출 하였다.

직무와 자격요건을 분석하는 경우에는 두 명 의 분석자가 각각의 직무내용과 자격요건을 주 요 요소를 추출한 후 일치되는 항목에 대해서 만 직무내용 및 자격요건 분류로 채택하였다. 두 명의 분석자에 대한 코딩의 일치율은 $91 \%$ 로 나타났고, 채택된 항목에 대하여 빈도는 재 산출되었다.

〈표 2〉사서직 유형분류표

\begin{tabular}{c|l|l}
\hline 번호 & \multicolumn{1}{|c|}{ 사서직 유형 } & \multicolumn{1}{c}{ 세부 업무 내용 } \\
\hline 1 & 일반 & 도서관 서비스의 모든 업무에 참여하는 경우 \\
\hline 2 & $\begin{array}{l}\text { 행정 및 운영 } \\
\text { (adiministration \& management) }\end{array}$ & 관장, 부서장, 행정 및 홍보, 인사. 예산 등 \\
\hline 3 & $\begin{array}{l}\text { 열랍 및 대출 } \\
\text { (access services \& circulation) }\end{array}$ & 대출 \\
\hline 4 & 참고(reference) & 대인 참고봉사 및 온라인 참고봉사 \\
\hline 5 & 수서정리(technical services) & 목록, 분류, 서지, 수서, 장서개발 \\
\hline 6 & $\begin{array}{l}\text { 정보시스템 및 기술 } \\
\text { (information systems \& technologies) }\end{array}$ & 윕 관리, 디지털 프로젝트, 도서관 시스템, 각종 웹기반 어플리케이션 \\
\hline 7 & 교육(instruction) & $\begin{array}{l}\text { 교육, 이용자교육, 도서관교육, 서지교육, 원격교육지원, 온라인튜토리얼, } \\
\text { 정보활용교육, 미디어교육, 연구지원 }\end{array}$ \\
\hline 8 & 특수자료(special collection) & 정부자료, 멀티미디어, 스페설 콜렉션 \\
\hline 9 & 주제전문가(subject librarian) & 법, 의학, 과학, 인문사회학, 예술 \\
\hline 10 & $\begin{array}{l}\text { 기록보존 } \\
\text { (archive \& record management) }\end{array}$ & 기록관리, 기록보존 \\
\hline
\end{tabular}




\section{2 사서직 구인광고 유형별 분포}

3년간 대학도서관, 공공도서관, 전문도서관, 기관도서관 - 자료실, 학교도서관 에서 게재한 구인광고는 총 1,323 건으로 대학도서관 구직광 고가 $60 \%$, 공공도서관구직광고가 $34 \%$ 로 나타 났고, 두 유형의 도서관에서 게재한 광고가 전 체의 $94 \%$ 를 차지하여 구인광고의 대부분에 해 당하는 것으로 나타났다(표 3 참조).

각 사서직 유형별 구인광고를 연도별로 살펴 본 〈표 4〉에 따르면 교육에 관련된 사서 구인광 고는 2004년 41건, 2005년에 가장 많은 58건으 로 나타났고, 2006년에는 전년 대비 약 $43 \%$ 가
감소한 33 건으로 조사되었다. 2006년의 전체 광고건수가 2005 년에 비하여 $26 \%$ 감소한 것과 비교하면 교육관련 사서 구인광고가 크게 줄었 다는 것을 알 수 있다.

전체 구인 광고 수에서 교육 관련 광고가 차지 하는 비율은 $7 \%$ 로 행정 - 운영 $26 \%$, 참고 $18 \%$, 수서 $12 \%$, 일반 $10 \%$, 주제전문가 $9 \%$ 에 이어 6 번째로 나타났다. 분석대상인 'American Libraries'는 미국 전역을 대상으로 하고 있어 미국 도서관의 기관지적인 성격이 있어 상대적으로 전국에서 모집하는 경우가 많은 관장이나 부서 장 구인광고가 많은 특성이 있었다. 또한 전문 성을 명시하지 않은 일반 사서 광고를 제외하

〈표 3〉도서관 유형별 구인광고 게재 건 수

\begin{tabular}{c|c|c|c|c|c|c}
\hline \multirow{2}{*}{ 구 분 } & \multicolumn{2}{|c|}{2004 년 } & \multicolumn{2}{c|}{2005 년 } & \multicolumn{2}{c}{2006 년 } \\
\cline { 2 - 7 } & 건 & 비율 & 건 & 비율 & 건 & 비율 \\
\hline 대학도서관 & 276 & $63.9 \%$ & 280 & $55.2 \%$ & 238 & $62.0 \%$ \\
\hline 공공도서관 & 124 & $28.7 \%$ & 207 & $40.8 \%$ & 123 & $32.0 \%$ \\
\hline 전문도서관 & 14 & $3.2 \%$ & 15 & $3.0 \%$ & 6 & $1.6 \%$ \\
\hline 기관도서관 & 15 & $3.5 \%$ & 3 & $0.6 \%$ & 15 & $3.9 \%$ \\
\hline 학교도서관 & 3 & $0.7 \%$ & 2 & $0.4 \%$ & 2 & $0.5 \%$ \\
\hline 총 계 & 432 & $100.0 \%$ & 507 & $100.0 \%$ & 384 & $100.0 \%$ \\
\hline
\end{tabular}

〈표 4〉 구인광고에서 나타난 사서직 유형분포

\begin{tabular}{c|l|r|r|r}
\hline 번호 & \multicolumn{1}{|c|}{ 사서직 유형 } & \multicolumn{1}{c|}{2004 년 } & \multicolumn{1}{c|}{2005 년 } & \multicolumn{1}{c}{2006 년 } \\
\hline 1 & 일반 & $54(9.2 \%)$ & $84(12.2 \%)$ & $55(10.9 \%)$ \\
\hline 2 & 행정 및 운영(adiministration \& management) & $158(26.9 \%)$ & $164(23.9 \%)$ & $154(30.6 \%)$ \\
\hline 3 & 열람 및 대출(access services \& circulation) & $30(5.1 \%)$ & $15(2.2 \%)$ & $23(4.6 \%)$ \\
\hline 4 & 참고(reference) & $97(16.5 \%)$ & $152(22.2 \%)$ & $73(14.5 \%)$ \\
\hline 5 & 수서정리(technical services) & $78(13.3 \%)$ & $72(10.5 \%)$ & $65(12.9 \%)$ \\
\hline 6 & 정보시스템 및 기술(information systems \& technologies) & $33(5.6 \%)$ & $60(8.7 \%)$ & $31(6.2 \%)$ \\
\hline 7 & 교육(instruction) & $41(7.0 \%)$ & $58(8.5 \%)$ & $33(6.6 \%)$ \\
\hline 8 & 특수자료(special collection) & $20(3.4 \%)$ & $19(2.8 \%)$ & $20(4.0 \%)$ \\
\hline 9 & 주제전문가(subject librarian) & $66(11.2 \%)$ & $56(8.2 \%)$ & $45(8.9 \%)$ \\
\hline 10 & 기록보존(archive \& record management) & $10(1.7 \%)$ & $6(0.9 \%)$ & $4(0.8 \%)$ \\
\hline \multicolumn{2}{|r|}{ 계 } & $587(100.0 \%)$ & $686(100.0 \%)$ & $503(100.0 \%)$ \\
\hline
\end{tabular}


고 나면 전문성을 요구하는 구인광고 영역에서 는 교육관련 사서가 대출 사서 구인광고 $(3 \%)$ 와 특수자료 사서 $(3 \%)$ 의 약 2 배에 해당하는 비 율을 나타내었고, 정보기술 관련 사서직 $(6 \%)$ 보다도 수요가 많은 것으로 나타났다. 이러한 결과는 점차적으로 교육 담당 사서직이 도서관 의 사서직 유형으로 분야를 형성하는 것으로 해석할 수 있다.

교육관련 사서 구인광고를 게재한 주체를 유 형별로 교차분석한 결과에서 대부분의 교육 관 련 사서광고는 대학도서관(125건)에서 게재한 것으로 나타났고, 공공도서관은 2건, 기관도서 관은 3 건, 학교도서관이 2 건 게재한 것으로 조 사되었다.

\section{4. 교육관련 사서의 직무 및 자격요건}

\section{1 교육사서 직명에서 나타나는 관련 업무} 교육사서의 사서직명은 총 132 건에 대해 90
개의 직명으로 매우 다양하게 나타났다. 그중 가장 많은 숫자를 보여준 사서직명은 'reference/ instruction librarian(17건)'으로서 교육관련 업무가 참고사서의 업무와 결합하여 발전하고 있는 현상을 보여주고 있었다. 이와 같은 현상 은 〈표 5>와 같이 사서직명에 포함되어 있는 단 어 중 전치사, 접속사, librarian, library와 같은 일반단어를 제외하고 빈도수로 상위 10 개를 추 출한 경우에도 유사하게 나타나고 있다. 교육 을 직접적으로 표현하는 용어인 instruction을 제외하면 reference가 가장 출현 빈도가 높은 것 으로 나타나 교육관련 사서직명에 결합하여 명 기할 정도로 참고사서와 교육관련 사서 역할이 연관되어 있음을 알 수 있다. 특히 교육사서 직 명에 대한 단어빈도의 3 위부터 빈도수가 급격히 감소하는 순위까지 살펴보면 약 $30 \%$ 에 해당하 는 교육관련 사서직명에 공통적으로 'reference' 가 포함되어 있는 것은 교육사서가 참고사서의 영역에서 전문성을 가진 세부 영역으로 발전되 어나가고 있음을 제시하고 있다고 해석할 수 있다.

〈표 5〉 사서직명에서 나타나는 단어 빈도 상위 10 개

\begin{tabular}{c|l|c}
\hline 순 위 & 단 어 & 빈 도 \\
\hline 1 & instruction & 36 \\
\hline 2 & reference & 28 \\
\hline 3 & instructional & 9 \\
\hline 4 & information & 8 \\
\hline 5 & learning & 8 \\
\hline 6 & education & 7 \\
\hline 7 & instructor & 6 \\
\hline 8 & literacy & 6 \\
\hline 9 & research & 6 \\
\hline 10 & collection development & 5 \\
\hline
\end{tabular}


〈표 6〉 교육관련 사서 구인관고에서 나타난 주요 직무

\begin{tabular}{|c|c|c|}
\hline 순위 & 담당업무 & 빈도 수 \\
\hline 1 & 참고봉사 & 56 \\
\hline 2 & 교육(instructional) 프로그램 & 50 \\
\hline 3 & 장서개발 & 41 \\
\hline 4 & 정보활용(information literacy) 프로그램 & 32 \\
\hline 5 & 도서관교육 & 27 \\
\hline 6 & Liason 프로그램 & 22 \\
\hline 7 & 정보활용교육과 강의 연계 & 20 \\
\hline 8 & 강의 & 20 \\
\hline 9 & 연구지원및 컨설팅 & 17 \\
\hline 10 & 웹기반 교육 서비스 개발/관리/ 운영 & 16 \\
\hline 11 & 교육프로그램 설계 및 개발 & 13 \\
\hline 12 & 정보활용 프로그램 설계 및 개발 & 12 \\
\hline 13 & 아웃리치(outreach) 서비스 & 12 \\
\hline 14 & 원격교육/이러닝/온라인교육 지원 & 11 \\
\hline 15 & 행정 & 8 \\
\hline 16 & 전자정보원 및 어플리케이션 접근 관리 & 7 \\
\hline 17 & 서지교육 & 6 \\
\hline 18 & 교육프로그램 평가 & 5 \\
\hline 19 & 연구 & 5 \\
\hline 20 & 도서관교육관련 자료관리 & 4 \\
\hline 21 & 글짓기 강의와 연계 & 4 \\
\hline 22 & 연구/교육관련 협력업무 & 3 \\
\hline 23 & 도서관정책 & 3 \\
\hline 24 & 연구지원자료 생산 & 3 \\
\hline 25 & 참고사서교육/스태프교육 & 2 \\
\hline 26 & 강의용 어플리케이션 담당 & 2 \\
\hline 27 & 전자정보원 지정(reserve) & 2 \\
\hline 28 & 교육프로그램 홍보 & 2 \\
\hline 29 & 정보활용프로그램 홍보 & 2 \\
\hline
\end{tabular}

\section{2 교육사서의 주요 직무}

교육사서의 구인광고에서 나타난 주요 직무 는 총 29개로 나타났고, 가장 높은 빈도수를 차 지한 직무는 '참고봉사'로 56건이었다(표 6 참 조). 사서직명에 직접적으로 'reference'가 포 함되어 있는 사례가 28건이었던 것과 비교하자 면, 직종명에 구체적으로 명기되어 있지 않아
도 실제 직무에서는 참고봉사가 포함되는 비율 은 2 배로 높게 나타나 참고봉사업무가 교육사 서의 주요업무로 나타났다. 또한 교육과 관련 된 직접적인 직무는 '교육프로그램(50건)', '정보 활용 프로그램(32건)', '도서관 교육(27건)', '정 보활용 교육과 강의연계(20건)', '강의(20건)' 등 으로 상위순위에 분포되어 나타났지만 참고봉 사의 경우 다른 유사한 항목으로 분산되지 않 
고 집중되었기 때문에 최상위를 차지한 것으로 분석된다. 'Liason 프로그램'이 참고봉사의 한 영역으로도 해석될 수 있으나, 'Liason 프로그 램'의 경우에는 학과나 학부를 전담하는 경우 가 상당수 포함되어 있어 전담사서의 경우 장 서개발, 교육프로그램 운영, 참고봉사. 각종 지 원 등 복합적인 업무로 보는 것이 합리적이다.

참고봉사와 마찬가지로 전통적인 도서관 업 무 중 교육관련 사서의 주요 직무로 나타난 '장 서개발은 41건으로 매우 높은 빈도수를 보여 주었다. 장서개발이 상위빈도로 나타난 것은 주목할 만한 사항으로 도서관에서의 교육은 도 서관 장서를 기반으로 하는 교육이어야 그 영 향력이 극대화되고 활성화된다는 점에서 다른 부서나 기관에서 하는 교육과 차별화 될 수 있 다는 특성을 보여주고 있다. 다시 말해 풍부한 정보원 확보와 정보원 이용에 대한 노하우가 도서관이 새로운 교육담당 기관으로서 차별화 되는 요소라 할 수 있다. 특히, 도서관이 지원하 는 원격교육, 이러닝, 온라인 교육 등의 경우 적 절한 정보원 확보가 매우 중요한 이슈이다. 따 라서 교육담당 사서는 도서관에서 운영하는 교 육관련 활동을 효과적으로 운영하기 위해서는 장서개발에 참여하는 것이 주요 업무로 규정되 어 있는 것이 합리적이며 구인광고에서도 명시 되는 빈도가 높아지게 된 것이다.

사서가 직접적으로 교육을 실시하는 '강의' 가 20 건으로 상위에서 나타났고 '동료사서와 직원을 교육하는 업무도 2건으로 나타나 교육 담당 사서의 경우 교육자로서의 역할도 주요. 영역으로 형성되고 있는 것을 알 수 있다. 이 연 구의 직무분석에서 규정된 '강의'는 'teaching' 에 해당하는 것으로 강의실 강의로 제한된 것
인데 각종 교육 프로그램과 정보활용 프로그램 에서 교육하는 사례까지 포함하면 실제로 직접 적으로 사서가 교육을 하는 경우는 더 높은 것 으로 나타날 것으로 예상할 수 있다. 또한 '정보 활용 교육과 강의연계'의 경우도 20 건으로 나 타난 강의와 마찬가지로 비교적 높은 빈도에 해당하므로 미래의 도서관 교육활동은 도서관 으로 이용자를 불러 교육하는 형태가 아닌 교 육현장으로 도서관이 찾아가는 방향으로 발전 할 가능성을 보여주고 있다.

\section{3 교육사서의 주요 자격요건}

교육사서의 주요 직무를 수행하기 위해서 필 요로 하는 주요 경험 및 기술, 능력, 교육적 배 경은〈표 7〉에서 제시되어 있듯이 총 36 개 항 목으로서 직무분석과 동일하게 '참고봉사' 경험 이 가장 중요한 자격요건으로 나타났다. 직무 분석과 유사한 현상을 보이는 것은 '장서개발 업무 항목도 해당하는데 도서관 기존 업무 중 참고봉사와 장서개발이 고육담당 사서와 가장 관련있는 업무이며 복합적으로 수행되기를 기 대하는 업무로 해석된다.

두 번째 중요한 능력으로 나타난 항목은 '구 두(oral)/기술(written) 커뮤니케이션 능력'으 로 교육 담당 사서의 경우 중요한 능력은 다양 한 매체로 원활한 의사소통과 정보전달을 할 수 있는 능력이 핵심인 것으로 밝혀졌다. 그 다 음으로 많은 빈도를 나타낸 주요 능력은 ‘웹 서 비스 관리 및 웹 제작(23건)', '정보기술과 웹에 대한 지식(23건)'으로서 웹에 대한 지식과 웹 의 주요한 정보기술을 다룰 수 있는 능력이 교 육 담당 사서에게는 교육 경험보다 많이 요구 
〈표 7〉 교육관련 사서 구인광고에서 나타난 주요 자격 요건

\begin{tabular}{|c|c|c|}
\hline 번호 & 자격요건(교육/경헙/능력/기술) & 빈도수 \\
\hline 1 & 참고봉사 업무 & 36 \\
\hline 2 & 원활한 구두/기술 커뮤니케이션 능력 & 28 \\
\hline 3 & 웹서비스 관리 및 웹제작 능력 & 23 \\
\hline 4 & 정보기술/웹에 대한 지식 & 23 \\
\hline 5 & 교육 업무 & 21 \\
\hline 6 & 원활한 대인관계 & 18 \\
\hline 7 & 장서개발 업무 & 17 \\
\hline 8 & 문헌정보학의 주제 분야 지식 & 16 \\
\hline 9 & 개방적 업무 수행능력 & 15 \\
\hline 10 & 강의경험 & 14 \\
\hline 11 & 정보활용 동향에 대한 지식 & 14 \\
\hline 12 & 도서관교육 관여 경혐 & 13 \\
\hline 13 & 정보원 전반 & 13 \\
\hline 14 & 협력업무 능력 & 13 \\
\hline 15 & 문헌정보학외 주제분야의 석박사 학위 & 11 \\
\hline 16 & 정보활용 프로그램 관여 경험 & 11 \\
\hline 17 & 행정/예산 관여 & 11 \\
\hline 18 & 독립적 업무 수행능력 & 9 \\
\hline 19 & 원격교육/이러닝 관여 경험 & 8 \\
\hline 20 & 전자정보원에 대한 지식 & 8 \\
\hline 21 & 온라인 교육 프로그램 & 7 \\
\hline 22 & 강의/커리큘럽 개발 & 6 \\
\hline 23 & 연구/학술활동 & 6 \\
\hline 24 & 정보활용기준에 대한 지식 & 5 \\
\hline 25 & 코스웨어 운영 & 5 \\
\hline 26 & 교윺자료/가이드 작성 & 4 \\
\hline 27 & 연구지원 & 4 \\
\hline 28 & 이용자봉사 & 4 \\
\hline 29 & 정보활용방법론 & 4 \\
\hline 30 & 교육설계 & 3 \\
\hline 31 & 그룹 교육 & 3 \\
\hline 32 & 리더십 & 3 \\
\hline 33 & 아웃리치 & 3 \\
\hline 34 & 교유관리 프로그램 & 2 \\
\hline 35 & 온라인 참고봉사 & 2 \\
\hline 36 & 인쇄정보원에 대한 지식 & 2 \\
\hline
\end{tabular}

되는 것으로 판명되었다.

교육사서가 갖추어야 할 지식을 살펴보자면 위에서 설명한 것과 같이 '웹' 관련 지식이 가장
높은 빈도를 차지했고 다음으로는 '문헌정보학 외 주제분야 지식'과 '정보활용 동향에 대한 지 식', '문헌정보학 외 주제 분야의 석 - 박사 학 
위' 순으로. 나타났다. 특히 문헌정보학 외 주제 분야 지식과 학위를 요구하는 현상을 살펴보자 면 주졔전문가로서의 교육담당 사서 역할도 기 대되고 있다는 것을 알 수 있다. 이는 직무분석 에서도 'liason 프로그램' 항목으로 나타나 교육 담당 사서의 경우 특정 주제분야의 전문지식으 로 특정 주제에 대한 교육프로그램을 특화하여 운영할 수 있는 교육자의 역할도 요청되는 것 으로 나타났다.

전반적으로 교육사서의 자격요건을 살펴보 면 직접적인 교육관련 경험만큼 '원활한 구두/ 기술 커뮤니케이선 능력', '대인관계 능력', '개 방적 업무 수행 능력 등 이 상위에 나타나 사서 의 전문지식과 더불어 업무 태도와 수행능력에 대한 기대치가 높은 것으로 나타났다.

\section{5. 결 론}

교육관련 사서직은 다양한 교육프로그램과 관련하여 역할의 범위도 새롭게 정의되는 사서 직의 새로운 전문 분야로 인식되어 왔다. 이 연 구에서 미국 도서관의 구인광고를 분석한 결과 교육관련 사서직은 다음과 같은 특성을 가지고 변화하고 있다.

첫째. 교육분야 사서직은 현재 대학 도서관 에서 필요성이 높아지고 있는 분야인데 이는 모기관의 성격과 관련된 것으로 파악된다. 대 학도서관의 교육활동은 지금까지의 학생과 교 원의 학습과 연구활동을 지원하는 활동에 머무 르지 않고, 강의와 커리큘럼 개발과 같이 직접 적으로 교육에 참여하는 형태로 변화하고 있다. 참고봉사의 일환으로 도서관 이용 교육이나 서
지교육의 범위 내에서 수행되고 있던 교육관련 활동들이 점점 더 직접적인 형태로 변화하면서 사서직의 역할이 정보제공자와 도서관 안내자 에서 교육자의 역할까지 포함하여 확장되는 현 상이 나타났다. 이러한 점은 사서직의 직무내 용에 '강의경험'이 포함된 광고건수가 132 건 중 14 건으로 약 $10.6 \%$ 에 해당한다는 조사결과에 도 반영되어 있다. 또한 원격교육과 이러닝을 통해 도서관의 정보자원을 직접적으로 교육에 투여하는 등 교육참여 형태가 점점 다변화되고 있다. 반면 공공도서관 분야에서는 연구자들이 교육활동의 중요성을 인식하였으나 아직 교육 전문 사서직 수요가 드러나고 있지는 않았다.

둘째, 기존 도서관 업무 중 참고영역과 장서 개발 영역이 교육사서의 영역과 밀접하게 연관 관계를 가지고 있는 것으로 나타났다. 참고영 역은 전통적으로 이용자와 직면하여 서비스를 운영하는 부서로서 이용자 교육을 담당하는 부 서 중 하나로 인식되어 왔기 때문이다. 그러나 장서개발 영역이 중요한 영향을 미치는 것은 도서관의 역할 변화에 따른 것으로 대출을 목 적으로 장서를 개발하는 소극적 접근으로부터 교육을 위해 장서를 준비하는 적극적 접근 방 식으로 장서개발의 방항성을 제시하고 있다.

셋째, 교육사서에게도 웹 사이트 운영 및 정 보기술에 대한 지식, 온라인 어플리케이션 운 영 경험 등이 강조되고 있는 현상을 파악할 수 있다. 교육의 형태가 물리적 공간에서 대면을 통해 이루어지던 상황에서 점차적으로 네트워 크에서 온라인 정보원과 어플리케이션, 교수, 학습자가 결합되어 교육이 이루어지는 원격교 육 서비스로 발전되고 있는 교육현장의 변화가 교육사서에게도 영향을 미치는 것으로 파악된 
다. 또한 도서관의 자원과 이용체제도 전자정 보원과 디지털도서관으로 체제전환을 하고 있 기 때문에 양쪽 분야의 변화가 교육사서에게는 복합적인 요구사항으로 나타날 수 있다.

도서관에서 요구하고 있는 교육사서 모델은 교육 관련 서비스가 다양해지면서 여러 가지 이름으로 불리우면서 다양하게 나타나고 있지 만 직무를 분석한 결과 교육사서라는 새로운 전문사서영역이 나타나는 것이 아니라 참고봉 사 및 장서개발 등과 같은 기존의 정보서비스 와 결합하여 전문성이 규정되는 현상을 파악할 수 있었다. 또한 주제전문성, 정보기술에 대한 지식, 원활한 대인관계 및 커뮤니케이션 능력
등 교육사서의 역량에 대한 기대치도 교육 전 문 지식 외에도 다각도로 표현되고 있었다. 이 러한 인력에 대한 요구 현상은 미국의 경우 대 학도서관들을 중심으로 나타나고 있는데, 이와 같은 조건으로 업무를 수행하는 대학 도서관의 교육 사서들이 대학도서관의 서비스 활성화와 발전 방향 제시에 기여하는 바가 점차적으로 드러날 것으로 예측된다. 또한 이러한 현상은 전문성을 확보하고자 하는 대학도서관뿐만 아 니라 평생학습기관으로 발전방향을 모색하고 있는 공공 도서관에서도 주목해 보아야할 점이 며, 공공도서관에서도 교육사서의 영역을 형성 하는데 있어 고려해봐야 할 사항이다.

\section{참 고 문 헌}

안인자. 2005. 사서직 업무변화에 관한 연구. ${ }^{\circledR}$ 한 국비블리아학회자』, 16(1): 233-246.

이현실. 2007. 대학도서관 2.0에서 사서의 업무 방향.『한국비블리아학회지 , 18(1): 147165.

Auster, Ethel and Donna C. Chan. 2004. "Reference librarians and keeping up-todate." References \& Users Service Quarterly, 44(1): 57-66.

Fourie, Ina. 2004. "Librarians and the claiming of new roles: how can we try to make a difference?" Aslib Proceedings, $56(1): 62-74$.

Hoerman, H. L. and Furniss, K. A. 2001. "Education for provision of library services to distance learners: the role fo the LIS Schools." Journal of $\mathrm{Li}^{-}$ brary Administration, 32(1-2): 247257.

JoAnne and Thomas, Deborah. 2006. "Technical services job ads: change since 1995." College \& Research Libraries, 67(2): 136-145.

Kibridge, H. M. and DePalo, L. 2001. "The education function in a digital library environment: a challenge for college and research libraries." The Elctronic

Lynch, Beverly P. and Smith, Kimberly Robles. 2001. "Changing nature of work Library, 19(5): 283-95. 
in academic libraries." College \& Research Libraries, 62(5): 407-420.

Marcum, I. W. 2002. "Rethinking information literacy." The Library Quarterly, 72(1): 1-26.

Seaman, Scott. 2007. "Salary compression: A time-series ratio analysis of ARL po- sition classification." Libraries and the Academy, 7(1): 7-24.

Shank, John D. 2006. "The Blended librarian: A job announcement analysis of the newly emerging position of instructional design librarian." College \& Research Libraries, 67(6): 515-524. 